\title{
CORRIGENDUM
}

\section{The microenvironment of classical Hodgkin lymphoma: heterogeneity by Epstein-Barr virus presence and location within the tumor}

R Wu, A Sattarzadeh, B Rutgers, A Diepstra, A van den Berg and L Visser

Blood Cancer Journal (2018) 8, e622; doi:10.1038/bcj.2017.102; published online 26 January 2018

Correction to: Blood Cancer Journal (2016) 6, e417; doi:10.1038/ bcj.2016.26

Since the publication of the paper the authors have noticed that $\mathrm{R}$ Wu was listed as the sole first author. This is incorrect; R Wu and
A Sattarzadeh contributed equally to this paper and are co-first authors.

The authors wish to apologize for any inconvenience caused. 